\title{
O lugar do BRICS na Política Externa da Índia
}

ASSOCIACÃO BRASILEIRA DE RELAÇÕES INTERNACIONAIS

ISSN $2526-9038$
Copyright:

- This is an open-access article distributed under the terms of a Creative Commons Attribution License, which permits unrestricted use, distribution, and reproduction in any medium, provided that the original author and source are credited.

- Este é um artigo publicado em acesso aberto e distribuído sob os termos da Licença de Atribuição Creative Commons, que permite uso irrestrito, distribuição e reprodução em qualquer meio, desde que $o$ autor $\mathrm{e}$ a fonte originais sejam creditados.

\author{
The BRICS place in India's \\ Foreign Policy \\ El lugar de los BRICS en la \\ política exterior de India
}

DOI: $10.21530 /$ ci.v16n2.2021.1118

Sandra Aparecida Cardozo ${ }^{1}$

\section{Resumo}

O artigo apresenta a participação da Índia no mecanismo BRICS, um grupo de países heterogêneos. Diante das diversidades dos componentes, o objetivo é mostrar elementos da política externa da Índia por demandas e interesses no agrupamento. Para isso, são examinados aspectos do conceito de não alinhamento e multilateralismo; a Índia na primeira década do mecanismo e a construção de agendas; a relação da Índia com os demais países do BRICS e com a China, particularmente. Por fim, conclui-se que a troca de governos, nesse período, não alterou os princípios do multilateralismo seletivo e da autonomia estratégica.

Palavras-chave: BRICS; Política Externa da Índia; Multilateralismo; Relações Índia-China.

\section{Abstract}

The article presents the participation of India in the BRICS mechanism, a group of heterogeneous countries. Given the diversity of the components, the aim is to show elements of India's foreign

\footnotetext{
1 Doutora em Ciência Política pela Unicamp. Professora Associada da Universidade Federal de Uberlândia, Minas Gerais, Brasil. (sandraczo@ufu.br).

ORCID: https://orcid.org/0000-0002-0091-2929

Artigo submetido em 26/08/2020 e aprovado em 01/03/2021.
} 
policy by demands and interests in the grouping. To this end, aspects of the concept of nonalignment and multilateralism are examined; India in the first decade of the mechanism and the agenda building; India's relationship with the other BRICS countries and with China in particular. Finally, it is concluded that the exchange of governments in this period has not altered the principles of selective multilateralism and strategic autonomy.

Keywords: BRICS; Foreign Policy of India; Multilateralism; India-China Relations.

\section{Resumen}

El artículo presenta la participación de India en el mecanismo BRICS, un grupo de países heterogéneos. Dada la diversidad de componentes, el objetivo es mostrar elementos de la política exterior de India por demandas e intereses en la agrupación. Para ello, se examinan aspectos del concepto de no alineamiento y multilateralismo; la India en la primera década del mecanismo y la construcción de la agenda; la relación de la India con los demás países BRICS y con China en particular. Finalmente, se concluye que el intercambio de gobiernos en este periodo no ha alterado los principios de multilateralismo selectivo y autonomía estratégica.

Palabras clave: BRICS; Política exterior de la India; Multilateralismo; Relaciones India-China.

\section{Introdução}

O diálogo entre Brasil, Rússia e Índia, constituindo-se o BRIC, em 2009, e o BRICS, com a inclusão da África do Sul, em 2011, completou uma década em 2019. Originalmente criado por Jim O’Neill, na época chefe de pesquisas econômicas globais do banco de investimentos Goldmen Sachs, o acrônimo BRIC residia na caracterização desses países como grandes economias emergentes que estariam entre as maiores economias do mundo nos próximos 50 anos. Posteriormente, o termo popularizou-se principalmente no meio jornalístico e serviu, de forma recorrente, para comparações das variáveis econômicas entre os membros do grupo, definidos como "potências emergentes" com aspectos de preponderância regional e aspiração global.

Antes da primeira cúpula, na Rússia, em 2009, encontros regulares entre os ministros de Relações Exteriores de Brasil, Rússia, China e Índia passaram a ocorrer à margem da sexagésima primeira sessão da ONU, em 2006. Quando 
decidiram se reunir, a proposta era acompanhar encontros promovidos por organismos multilaterais para o exame de grandes temas da agenda internacional. A partir da primeira cúpula, o grupo começou a tomar um corpo próprio, com reuniões ministeriais, e o início de um diálogo foi formado para estabelecer formas de cooperação em áreas como energia, meio ambiente e comércio. De uma classificação econômica, passou a ocorrer, então, a efetivação de uma aproximação de âmbito político.

De um acrônimo a um grupo político, como definir o BRICS? Um conjunto de países que compartilham certos interesses, mas não formam uma aliança formal ou organização (Sakawa 2019). Constituem um grupo de países com diversos aspectos de valores e preferências políticas. Com peso econômico, geopolítico e populacional díspares, o grupo está longe de ser homogêneo, mas com uma disposição inicialmente de construir demandas comuns em determinados assuntos como mudança climática, comércio e desenvolvimento, interesses e objetivos de países em desenvolvimento (Thakur 2014).

A emergência do BRICS está dentro do contexto da crise financeira de 2008 e reflete uma necessidade de mudança no mundo econômico. A cooperação entre os membros residiu primeiramente em interesses comuns na esfera econômica, como a coordenação no G20, na proteção dos interesses do Sul Global nas crises financeiras globais, na promoção de reformas das instituições financeiras internacionais como o FMI e o Banco Mundial. O maior avanço institucional do grupo, na primeira década, foi na área financeira, com o NDB (New Development Bank) e o CRA (Contingent Reserve Arrangement), em 2014. O BRICS, nessa perspectiva, pode ser interpretado como uma promoção moderada na reforma da arquitetura da governança global (Li 2019).

No conjunto, os cinco países representam $40 \%$ da população global e $23 \%$ do PIB mundial, em 2018, com uma média maior de crescimento do que os países do G-7 nas últimas duas décadas. A participação no comércio mundial cresceu de 6\%, em 1995, para 16\% em 2015. No entanto, ao desmembrar o grupo, detecta-se uma grande disparidade em termos de crescimento econômico, pois somente a China e a Índia foram responsáveis por juntas contribuírem $45 \%$ do crescimento mundial em 2017. Entre 2003 e 2018, China e Índia cresceram $7 \%$ e 7,4\%, enquanto Rússia, Brasil e África do Sul cresceram, em média, 0,7\%, 0,2\% e 1,4\%, respectivamente, no mesmo período (Li 2019).

No que se refere à análise individual, é possível reconhecer que há disparidades internas no BRICS nos aspectos econômicos, mas também verificar que os países 
se conectam à dimensão de grupo por estratégias particulares. Enquanto a China precisa do BRICS não necessariamente por questões de comércio e segurança e sim para ter uma estrutura de cooperação que aumente a estabilidade no sistema internacional, a Rússia precisa principalmente no que diz respeito a sua segurança na Eurásia e autonomia em questões globais. Para a Índia e o Brasil, os aspectos de reivindicação de mais força nas negociações internacionais foram atrativos. As disparidades econômicas e os interesses geopolíticos particulares, além da existência de competição entre os membros em determinados temas, tornam a narrativa de ascensão em conjunto do BRICS fluida.

Nessa perspectiva, este artigo não examina o BRICS como um mecanismo fechado, mas a participação de um país específico, a Índia, na relação e na construção do grupo através da abordagem de características marcantes da política externa. Assim, a questão que emerge é sobre quais os interesses da Índia no seu vínculo com o BRICS. Estaria no tradicional multilateralismo como contrapeso ao sistema das grandes potências? Como se sabe, o multilateralismo, para a Índia, historicamente, sempre foi definido como o âmbito da negociação, resolução de conflito, manutenção da segurança internacional e dos desafios econômicos e sociais mundiais (Alam 2017). Esses fatores decorrem do compromisso com o Movimento dos Não Alinhados, na sua origem, e com o sistema ONU, mas também de uma autonomia estratégica exercida pelo país.

Diante disso, o objetivo é demonstrar que, na política externa indiana, o BRICS estaria numa estratégia de múltiplos alinhamentos, numa trajetória de multilateralismo e liderança no Sul Global, com ênfase na defesa do desenvolvimento, sustentada dentro de uma tradição oriunda da lógica do não alinhamento com as grandes potências nos anos da Guerra Fria. Dessa forma, a Índia se enquadraria, no BRICS, numa subdivisão de IBAS (Diálogo Brasil, Índia e África do Sul) pelos elementos da promoção do desenvolvimento e da democracia e no RIC (Rússia, Índia e China) pelas dimensões de poder e geopolítica na Eurásia. Ainda, argumenta-se que esses fatores se sobrepõem à mudança entre dois governos ideologicamente diferentes, liderados por Manmohan Singh e Narendra Modi, a ponto de não alterar a estratégia do país no mecanismo BRICS.

Além dessa introdução, o artigo possui mais três seções. A primeira faz uma abordagem sobre a política externa da Índia à luz do conceito de não alinhamento, do lugar do multilateralismo e da concepção de autonomia estratégica. A segunda seção demonstra a participação indiana e a construção das agendas nas cúpulas do 
BRICS, entre 2009 e 2019, com destaque à ideia de um Banco de Desenvolvimento. Também traz as dimensões de governos diferentes, Singh e Modi, com estratégias similares de participação no grupo. A última seção demonstra a relação da Índia com os demais BRICS, particularmente com a China, pelo peso econômico no grupo. O destaque dado à China deve-se também pela rivalidade regional e pelas condições das relações sino-indianas para a própria existência do BRICS.

\section{A política externa da Índia e o lugar do multilateralismo}

Reconhecida como a maior democracia do mundo, a Índia figura entre os países do BRICS como o único que combina instituições democráticas liberais e um crescimento econômico contínuo por mais de duas décadas. Essa última característica colocou a Índia na concepção de Rising Asia, com um PIB de 2.875 trilhões de dólares, em 2019 (World Bank 2019), e um crescimento médio em torno de 6\% ao ano entre 2009 e 2018. Desde 2015, a Índia ultrapassou o PIB absoluto do Brasil e tornou-se a segunda maior economia do BRICS e a sétima maior do mundo. As dimensões militar e nuclear também localizam a Índia na condição de um importante global player. Por outro lado, com a segunda maior população do mundo, com 1.353 bilhões de habitantes aproximadamente, é o país com o maior número de pessoas em extrema pobreza, por volta de 300 milhões. Apesar do peso econômico, os desafios internos são enormes e vêm de longa data. Esses últimos indicadores localizam a Índia no conjunto de países em desenvolvimento com grande adesão às demandas por mudanças nas instituições internacionais.

Com a política externa do não alinhamento, orientada por bases inicialmente idealísticas, promovidas por Jawaharlal Nehru nos anos da Guerra Fria, a Índia exerceu liderança sobre os países menos desenvolvidos, o chamado Terceiro Mundo. Logo após a independência, em 1947, o nacionalismo se manteve como uma reação à dominação externa, justificando a unidade nacional como forma de suplantar os conflitos internos e construir a identidade como um país livre e contra ingerências. No plano internacional, a orientação era manter uma ordem pacífica, embora nem sempre possível, a cooperação com todos os países e não aderir a nenhum dos blocos. Num mundo dividido entre duas grandes potências, a Índia abriu espaço para um não comprometimento com os polos 
de poder, numa estratégia de sobrevivência e possibilidades de negociações quando o chamado interesse nacional estava em jogo, como a questão do desenvolvimento econômico com a proteção à indústria doméstica, através do conceito Sawaraj, ou de conflitos bélicos sem o comprometimento prévio com as grandes potências.

O caráter pacífico da política externa do não alinhamento se fez presente na Conferência de Bundung, em 1955, base para o Movimento dos Não Alinhados, onde houve a cooperação entre China e Índia, num princípio de coexistência pacífica indo-chinesa conhecida como Panchsheel. Após Bandung, a política externa indiana teve uma influência sobre os países em desenvolvimento e movimentos anticoloniais. Mas a eclosão de conflitos exigiu da Índia uma profunda transformação no manejo do não alinhamento, particularmente na relação com as grandes potências. Os desafios colocados por China e Paquistão à Índia, com repercussões devastadoras, moveu o país em direção às grandes potências e o não alinhamento passou a ser escolhas estratégicas num cenário de rivalidades regionais. Os casos mais marcantes dessa inflexão foram a ajuda dos Estados Unidos na guerra contra a China, em 1962, e o apoio fundamental da União Soviética na guerra contra o Paquistão, em 1971, por exemplo.

Hoje, a questão que emerge nas análises sobre política externa da Índia é se o legado do não alinhamento ainda continua como orientação. As reformas econômicas, as quais o país implementou no início dos anos 1990, conduziram a uma reorientação da política externa, na direção de um religamento com o ocidente, na medida da necessidade de acesso aos investimentos estrangeiros, mercado, tecnologia e, até mesmo, no anseio de ser um membro permanente no Conselho de Segurança da ONU e do Grupo de Supridores Nuclear. Esse movimento deixou o país mais alinhado com uma ordem liberal. Mukherji (2014) interpretou as reformas do início dos anos 1990 como a passagem da Índia do conflito estrutural para um liberalismo incorporado, porém sem praticar reformas de austeridade com as pressões do FMI. A aspiração à independência nas decision-making e uma postura ativa nas negociações internacionais, sem uma política de aliança militar, com uma visão de democratização do sistema internacional, permaneceram. Por esses aspectos, o aparato conceitual do não alinhamento ajudaria, e não seria um obstáculo, na integração da economia indiana dentro de uma ordem econômica política global dominada pelo ocidente (Alam 2017). 
Apesar da percepção de que o contexto e as capacidades do país mudaram completamente desde os anos de uma política externa orientada pelo não alinhamento, recomendações foram feitas no documento Non-alignment 2.0, lançado, em 2012, por analistas independentes e ex-formuladores da política externa. Nesse documento, foram feitas as defesas da autonomia estratégica e de uma ordem mais equitativa para a inserção internacional do país (Ollapally 2018).

Durante seis décadas, o não alinhamento permaneceu central na identidade política global da Índia e estaria sendo continuado no século XXI nos aspectos de autonomia na construção de alianças e posicionamentos nas dinâmicas regionais. Num cenário de ascensão da China, desafios se impõem entre os benefícios e os riscos nas relações com os vizinhos e nas redes de alianças criadas por diversos países. A autonomia estratégica, como vestígio do não alinhamento, estaria pautando tanto os custos de uma parceria estratégica com os Estados Unidos, promovida desde meados dos anos 2000, quanto os benefícios da parceria econômica com a China, assim como as relações com a Rússia (Pant e Super 2015).

Paralelo ao debate sobre a atualização da concepção do não alinhamento, as prioridades atuais do país são identificadas por três pilares da política externa segundo Wulf e Debiel (2015): o multilateralismo tradicional, o bilateralismo e o pertencimento aos clubes. Enquanto o multilateralismo diz respeito à atuação nos fóruns globais, o bilateralismo envolve as relações com parceiros importantes, tais como Rússia, Estados Unidos e os vizinhos, uma vez que a SAARC (South Asian Association for Regional Cooperation) tem baixa densidade de integração. Sobre as coalizões seletivas, os autores encontram um distanciamento da retórica enfatizada nos propósitos de direitos e equidades, mas as ações seriam de acordo com o aumento de interesses e oportunidades. Nas relações bilaterais, a Índia aprofundou parcerias estratégicas com os Estados Unidos e mantém forte as relações militares com a Rússia, assim como parceria estratégica com Israel e Japão, por exemplo. Com a China, o bilateralismo é o mote das relações, uma vez que os chineses se tornaram o maior parceiro comercial, em 2014, mas também no multilateralismo como BRICS e SCO (Shanghai Cooperation Organization). O multilateralismo adotado pela Índia, nos últimos anos, pode ser interpretado como uma estratégia de múltiplo alinhamento, onde o país estaria se tornando mais proativo em vários fóruns internacionais como no G-20, no BRICS e em organizações regionais no Leste Asiático e em domínios marítimos Indo-Pacífico (Berenwall 2016). 
Há uma característica identificada na forma de negociação da Índia na arena internacional que revela a variação do comportamento de acordo com qual país e em qual instância as negociações são executadas. Por exemplo, as negociações com os Estados Unidos envolvem cálculos estratégicos como o que culminou no Acordo Civil Nuclear, em 2005. Com os países do BRICS - apesar da Índia já ter atuado em várias coalizões, particularmente com o Brasil, seja na ONU ou seja no GATT, em outros momentos, e mais recentemente na OMC e no BASIC (Brasil, África do Sul, Índia e China), neste com a presença da China -, a estratégia da Índia para a negociação é conforme o interlocutor. No BRICS, o elemento de pertencimento estaria na base das causas enquanto país em desenvolvimento (Narlikar 2013).

A relação da Índia com países que compõem o BRICS, no âmbito da cooperação multilateral, foi precedida em várias outras instâncias nos anos 2000. A primeira foi a formação do Diálogo IBAS (Brasil, Índia, África do Sul), em 2003, através da Declaração de Brasília, num encontro entre os ministros das relações exteriores da Índia, Brasil e África do Sul. O IBAS, particularmente, teve como base a cooperação entre três grandes países democráticos e em desenvolvimento para consulta política e coordenação diplomática sobre temas de política internacional, como questões de segurança e a reforma da Organização das Nações Unidas e do Conselho de Segurança, em específico. No acordo, também foram determinadas consultas sobre inclusão e equidade social, pobreza, promoção de segurança alimentar, saúde, assistência social, meio ambiente e desenvolvimento sustentável, entre outros, além da fomentação de iniciativas nas áreas de ciência e tecnologia, defesa, educação e cultura.

No nível global, a Índia tradicionalmente enfatiza a necessidade de um mundo no qual o multilateralismo seja um contrapeso ao poder estabelecido, por esse motivo, a existência de demandas por mudanças em vários fóruns internacionais como FMI, Banco Mundial, OMC e ONU. As mudanças de cotas e votos no FMI vêm de longa data e entram nesse universo de demandas. Nesse sentido, a pauta de mudança nas instituições de Bretton Woods foi a que mais encontrou ressonância no BRICS. Após a crise financeira de 2008, o G-20 tornou-se a principal instância para o enfrentamento e possibilitou internamente a atuação conjunta dos países do BRICS. No âmbito do G-20, da OMC e do BASIC, foram coalizões mais pontuais no que diz respeito ao comércio e ao meio ambiente. 
No momento da formalização do BRIC, em 2009, o secular partido de Jawaharlal Nehru (1947-1962) do Partido do Congresso (Indian National Congress) estava à frente do governo da Índia, através da United Progressive Alliance (UPA), liderada por Manmohan Singh como primeiro ministro (2004-2014), que também foi Ministro das Finanças, em 1991, quando introduziu mudanças estruturais na economia durante o governo de Narasimha Rao. Diante da recessão econômica mundial ocorrida em 2008, o desafio para Singh era de que a Índia pudesse sustentar um crescimento rápido nos anos seguintes, uma vez que o quadro enfrentado era de desaceleração econômica global e volatilidade dos preços dos alimentos e da energia, conciliar o crescimento com objetivos ambientais, com as incertezas políticas no Oriente Médio e com a ascensão do terrorismo e do extremismo. Todos esses temas passaram a ser tratados nas cúpulas do BRICS, inclusive a defesa do reequilíbrio das cotas no FMI e no Banco Mundial.

Em entrevista dada no encontro, em Londres, do G-20, em 2009, Singh fez uma leitura de que o mundo que construiu as instituições de Bretton Woods já não era mais o mesmo, por isso, a necessidade de propiciar mudanças internas nessas instituições. Em seu discurso, ressaltou que a Índia não precisava de financiamento do FMI, mas o país estaria disposto a contribuir com os recursos para a instituição e promover o reequilíbrio das cotas em favor dos países em desenvolvimento (Singh 2009). Essa reivindicação foi levada ao âmbito do BRICS e se transformou em um dos principais temas do agrupamento.

Nas eleições parlamentares indianas de 2014, a vitória do partido BJP (Bharatiya Janata Party), caracterizado por um nacionalismo hinduísta, marcou uma mudança significativa na política interna do país, pois teve a maior bancada no parlamento, nos últimos 30 anos, ficando à frente da coalizão NDA (National Democratic Alliance). O BJP já havia governado entre o final dos anos 1990 e o início dos anos 2000 e conduziu os testes nucleares de 1998. O primeiro ministro Narendra Modi, ex-governador do Estado de Gujarat, foi eleito com o discurso de revitalizar a força econômica da Índia e a questão que emergiu foi quais seriam os contornos da política externa. Centrada no conceito de "autonomia estratégica", a política externa de Modi não sofreu grandes alterações em comparação com o Partido do Congresso que o antecedeu e foi predominante nos governos pósindependência (Bergenwall 2016).

Num artigo que reflete sobre os dois primeiros anos da política externa sob o governo de Modi, Ashley Tellis, especialista em assuntos estratégicos asiáticos, 
expôs que Modi surpreendeu ao reforçar laços com vizinhos asiáticos, dos mais próximos aos mais distantes como Japão e Austrália, além de reafirmar as relações com os parceiros ocidentais tradicionais, bem como com a Rússia, e se aproximar pessoalmente do primeiro ministro do Paquistão, naquele período, Nawaz Sharif (Tellis 2016). Numa perspectiva de longo prazo, com o início do governo liderado pelo BJP, não houve mudança significativa com países chave como Estados Unidos, China, Paquistão e Rússia (Miller 2014).

A política externa de Modi não promoveu qualquer retração nas relações com os Estados Unidos, uma parceria estratégica iniciada ainda no governo de Singh, que promoveu o acordo nuclear civil com aquele país em parceria com o governo de George W. Bush. Enquanto a Rússia continua a ser um grande supridor de material de defesa e bilateralmente importante para o comércio, com a China, Modi trabalha com um potencial de entendimento, se distanciando um pouco de seus antecessores e mantendo restrições às ambições regionais chinesas. $\mathrm{O}$ BRICS entra na política externa de Modi como um investimento numa plataforma não ocidental (Pant e Super 2015; Pant 2017).

As elevadas taxas de crescimento econômico, ao mesmo tempo que mantêm o país mais alinhado com uma ordem liberal, sem ceder ao abandono da autonomia, impõem um pragmatismo na política externa (Ollapally 2018). Sobre esse aspecto, há um forte entendimento de que esse pragmatismo predominou a partir do final da Guerra Fria, em oposição ao idealismo nerhuviano. Ao classificar como processual, Miller e Estrada (2017) argumentam que o pragmatismo na política externa indiana é um processo de engajamento com todas e quaisquer ideias que forem contextual e politicamente oportunas para uma finalidade política. Esse argumento se contrapõe aos defensores de que a política externa de Modi seria mais pragmática do que a de seu antecessor, Manmohan Singh. Constrangimentos internos e ideias institucionalizadas na política externa limitam grandes mudanças, que quando ocorrem, são em graus estreitos (Miller e Estrada 2017).

\section{BRICS: a mesma moeda de dois governos ideologicamente diferentes}

Na primeira cúpula do BRIC, em 2009, havia uma defesa da cooperação entre esses países para minimizar os efeitos pós-crise e uma demanda para que 
as economias emergentes e em desenvolvimento devessem ter maior peso e representação nas instituições financeiras internacionais, assim como a ênfase na necessidade de uma reforma abrangente da ONU (BRIC, 2009). Na segunda cúpula, em Brasília, em 2010, a temática financeira e o reconhecimento de maior participação dos membros do BRIC nas instituições financeiras FMI e Banco Mundial estiveram presentes, assim como a busca de entendimentos nos temas de comércio internacional, o desenvolvimento através dos Objetivos de Desenvolvimento do Milênio (ODMs), o combate à pobreza, as temáticas de energia, mudanças climáticas e terrorismo (Bric 2010). Na ocasião da segunda cúpula, Manmohan Singh associou os temas de energia e segurança alimentar como possibilidades de cooperação, bem como a capacidade de produção e consumo de produtos agrícolas entre os países do grupo, destacou o papel dos componentes como uma voz importante nas negociações climáticas a partir da Conferência de Copenhagen e defendeu que esses países estariam numa posição única para a reforma da arquitetura da governança global (Singh 2010).

O encontro de Sanya, na China, em 2011, marcou o ingresso da África do Sul no BRICS, mesmo ano em que os cinco países estavam no Conselho de Segurança da ONU, aspecto ressaltado na declaração conjunta daquele encontro. No ano de 2011, também houve a eclosão de conflitos no Norte da África e no Oriente Médio, particularmente os casos da Líbia e da Síria, alvos de resoluções no Conselho de Segurança. Na declaração do encontro, projetou-se a continuidade de uma coordenação dos países na questão da Líbia no âmbito do Conselho de Segurança, assim como uma reforma abrangente da ONU. A declaração também reafirmou intenções de cooperação nas mais amplas temáticas como a coordenação da ação internacional contra o terrorismo, a necessidade de regulação do mercado de commodities, segurança alimentar, energia, clima, redução da pobreza, energia nuclear para fins pacíficos, a reforma do FMI, presentes nas declarações anteriores. Ainda, o desejo de um sistema de reservas internacionais para estabilidade e segurança monetárias e da conclusão da Rodada de Doha de desenvolvimento (Brics 2011). Em Sanya, o discurso de Manmohan Singh foi ao encontro dos temas expostos na declaração, como a disposição para a conclusão da Rodada de Doha, e ressaltou o papel da China em suportar as consequências da crise econômica e financeira mundial, além da capacidade da Índia em atrair investimentos (Singh 2011).

Na quarta cúpula dos BRICS, ocorrida em Nova Dehli, em 2012, além da 
reprodução dos assuntos dos encontros anteriores, projetos foram alçados nas esferas monetária e financeira com o Acordo Quadro para Extensão de Facilitação de Crédito em Moeda Local, no âmbito do Mecanismo Interbancário de Cooperação do BRICS e do Acordo para Facilitação de Confirmação de Cartas Multilaterais de Crédito entre os bancos de desenvolvimento dos países, para permitir financiamento de comércio e investimento em moeda local. Novamente o compromisso de cooperação dentro da ONU foi salientado, mas o marco do encontro foi estabelecer o projeto de criação de um Novo Banco de Desenvolvimento, com a finalidade de financiar projetos de infraestrutura e de desenvolvimento sustentável com abrangência dos países do BRICS e de outros países em desenvolvimento (Brics 2012).

A ideia de um Banco de Desenvolvimento surgiu do governo indiano como uma proposta para organizar um Banco de Desenvolvimento Sul-Sul, fundado e gerenciado pelo BRICS, com abrangência a outros países em desenvolvimento, numa leitura de deficiências na governança global em que instituições criadas há mais de seis décadas não acompanham as transformações mundiais (Singh 2012). Motivada por condições internas, a posição da Índia era criar um banco para ser um meio de financiamento das suas próprias necessidades em infraestrutura.

O NDB (New Development Bank) não configuraria para a Índia uma substituição do FMI e do Banco Mundial, mas uma segurança necessária em momentos de crise, uma vez que os países do Sul Asiático são muito pouco integrados economicamente (Alam 2017). Cozendey (2015) elenca alguns pontos da defesa indiana para efetivar um banco de desenvolvimento como, além de promover projetos de infraestrutura, ser um complemento de cooperação com as instituições financeiras multilaterais; favorecer a possibilidade de maior participação de países desenvolvidos na estrutura de capital do banco; não permitir operações com países em desenvolvimento não membros. A Índia também defendeu contribuições equivalentes para o capital e poder de voto igual para todos os membros fundadores (Cozendey 2015).

Em 2013, no encontro do BRICS, em Durban, para quinta cúpula, com a proposta do NDB em andamento, agregou-se a criação de um Arranjo Contingente de Reservas (ACR) como segurança financeira desses países (Brics 2013). Esse encontro foi observado por Manmohan Singh como um momento de fechamento do primeiro ciclo do grupo, onde o NDB poderia aprofundar a cooperação e, a despeito das diversidades, criaria sinergia entre esses países (Singh 2013). 
Nos primeiros anos, o BRICS tomou espaço na política externa da Índia como um mecanismo de demandas por reformas de instituições de governança global econômica e política, através de uma atuação multilateral, assim como um espaço para posições sobre assuntos de segurança e terrorismo, sobre o conflito na Síria, o processo de paz no Oriente Médio, sobre a Responsabilidade ao Proteger, entre outros assuntos de interesse do país. Mas fundamentalmente a grande contribuição da Índia ao BRICS, quando o Partido do Congresso esteve à frente do governo (2009-2014), foi a proposição de um banco de desenvolvimento coordenado intrabloco.

O encontro da VI cúpula do BRICS, em Fortaleza, em 2014, marcou a primeira grande viagem de Modi (2014-atual) para assuntos multilaterais, ocasião da efetivação do Acordo Constitutivo do Novo Banco de Desenvolvimento e da declaração de interesse da Índia em assumir a presidência da nova instituição. O NDB foi lançado com um capital subscrito de US\$ 50 bilhões e um capital inicial de US\$ 100 bilhões, distribuído igualmente entre os membros fundadores. Também foi estabelecido o tratado para o Arranjo Contingente de Reservas do BRICS com US\$ 100 bilhões iniciais (Brics 2014). Apesar do governo indiano reivindicar a sede e a presidência do NDB, no Acordo de Fortaleza, a Índia ficou com a primeira presidência e a sede foi estabelecida em Xangai, na China. Todos os outros países ficaram com vice-presidências. Para além da maturação institucional, a sexta cúpula reproduziu um panorama das antigas reivindicações como as das esferas financeiras, a valorização da ONU e das missões de paz, da UNCTAD e das possibilidades de resoluções de conflitos estendidos pelo mundo como o de Israel e Palestina. Nota-se o constante peso dado às Nações Unidas como o âmbito multilateral para a resolução de conflitos.

Em Fortaleza, Narendra Modi não divergiu dos discursos de seu antecessor, defendeu as reformas das instituições globais financeiras e do Conselho de Segurança e fez menção de que a ideia de um banco, lançada em Nova Délhi, dois anos antes, estava se tornando realidade. Ainda, ressaltou as várias modalidades de cooperação como tecnologia, turismo, comércio e opinou que o BRICS teria que se tornar um mecanismo com decisões mais tangíveis e de impacto concreto (Modi 2014).

Essas temáticas também estiveram presentes no encontro de 2015, em Ufa, na Rússia, embora com uma atualização dos conflitos existentes, como a situação da Ucrânia, que envolvia diretamente o país sede. O BRICS, com a afirmação 
conjunta na declaração de cúpula, defendeu que a solução para o conflito entre os dois países não deveria ser militar seguindo o Minsk by the Contact Group on Ukraine, apoiado pelos líderes da Rússia, Alemanha, França e Ucrânia e endossado pelo Conselho de Segurança da ONU na Resolução 2202 (BRICS, 2015). Em Ufa, o governo da Índia propôs a criação do BRICS Agriculture Research Platform, um centro para defender o desenvolvimento da agricultura sustentável, o alívio da pobreza e promover a segurança alimentar. Essa plataforma de pesquisa foi estabelecida, em 2016, através de um memorando de entendimento entre ministros de relações exteriores e implementada, com sede em Nova Delhi, em 2017.

Ainda no encontro de Ufa, num momento em que a Rússia estava sendo alvo de sanções, ocorreu, simultaneamente ao encontro do BRICS, o encontro da Organização Cooperação de Xangai, momento em que houve a decisão da admissão da Índia ao grupo (Shanghai Cooperation Organisation). O desejo indiano de incorporar-se ao SCO já havia sido manifestado, em 2011, na Declaração Conjunta entre Rússia e Índia (Lukin 2019).

Quando ocorreu o encontro de cúpula em Goa, em 2016, os problemas econômicos e políticos que afetavam o Brasil, agravados pela queda dos preços de petróleo e commodities, que também afetaram a Rússia, e problemas internos na África do Sul, expuseram o grupo a uma não sintonia em termos de crescimento econômico, quando a Índia estava crescendo a $8.0 \%$ ao ano e a China a quase $7 \%$ ao ano. Mas o mecanismo BRICS manteve-se como um espaço de interesse estratégico e econômico imediato para a Índia. O repúdio ao terrorismo, mais uma vez, tomou destaque na cúpula, além da ênfase nas instâncias multilaterais como ONU e OMC e nas mais variadas esferas de cooperação, entre as quais, agricultura, segurança alimentar, ciência e tecnologia (Brics 2016). Esse encontro do BRICS serviu para a Índia exercer sua liderança em assuntos de desenvolvimento (Chaturvedi e Saha 2019). Em Goa, também houve o encontro dos líderes do BRICS com os da BISMITEC (Bay of Bengal Initiative for Multi-Sectoral Technical and Economic Cooperation), composto por Bangladesh, Índia, Mianmar, Sri Lanka, Tailândia, Butão e Nepal, mais uma iniciativa da Índia.

Num contexto de tensão nas relações sino-indianas, o encontro em Xiamen, em 2017, foi realizado logo após divergências entre a China e a Índia, numa área de fronteira, na região de Doklam, quando, em junho daquele ano, a Índia tentou bloquear a construção de uma estrada por parte do governo chinês, enviando tropas e equipamentos. Superado diplomaticamente esse embate, a declaração 
assinada pelos membros do BRICS, na cúpula de Xiamen, foi protocolar em desejar paz, segurança, desenvolvimento, cooperação econômica e nas áreas de cultura, educação, saúde, tecnologia e na relevância das instituições de governança global já existentes. Os testes nucleares da Coreia do Norte, ocorridos também em 2017, foram rechaçados na declaração. Particularmente, sobre os interesses da Índia, um ponto fundamental tomou evidência no que diz respeito ao tema do terrorismo, pois, além do repúdio na declaração conjunta, com a condenação de ataques a países membros do BRICS, houve a denominação de grupos com práticas consideradas terroristas, entre os quais, Lashkar-e-Taiba e Jaish-e-Mohammad, com base no Paquistão (Brics 2017). Esse ponto pode ser interpretado como um ganho diplomático para a Índia pela condição de ser a primeira vez que o governo chinês assinou um documento, nesse caso, o BRICS Leaders Xiamen Declaration, em que aparecem nomes de grupos terroristas baseados no Paquistão (Rajagopalan 2017).

Os dois últimos encontros da primeira década do BRICS seguiram os parâmetros dos anteriores. Em 2018, em Johannesburg, com uma década do mecanismo BRICS, os compromissos para o fortalecimento do multilateralismo e da governança global, bem como a manutenção da cooperação, foram reafirmados. Em Brasília, na décima primeira cúpula de 2019, foram destacados o progresso institucional do NDB e do Arranjo Contingente de Reservas (ACR), o comércio e a economia digital (Brics 2018; Brics 2019). O encontro de 2019 foi a sexta participação de Narendra Modi em encontros de cúpula do BRICS e, em sua análise, o bloco precisa ser mais efetivo em algumas áreas como no aumento do comércio e do investimento intrabloco, considerados muito baixos. O combate ao terrorismo, através da cooperação do grupo, também foi expresso por Modi como um propósito do governo indiano, assim como o fortalecimento da ONU, OMC, Banco Mundial, reivindicações constantes na pauta dos BRICS.

\section{A relação da Índia com os BRICS e o desequilíbrio chinês}

Como apresentado, a origem do BRICS se deu em cima de uma prospecção de grandes economias. Desde a formação do mecanismo, em 2009, houve uma variação de crescimento dos países do grupo, a Índia e a China passaram a ser as economias que mais crescem no bloco e no mundo. 
Figura 1 - Taxa de crescimento do PIB dos países do BRICS de 2009 a 2019 (\%)

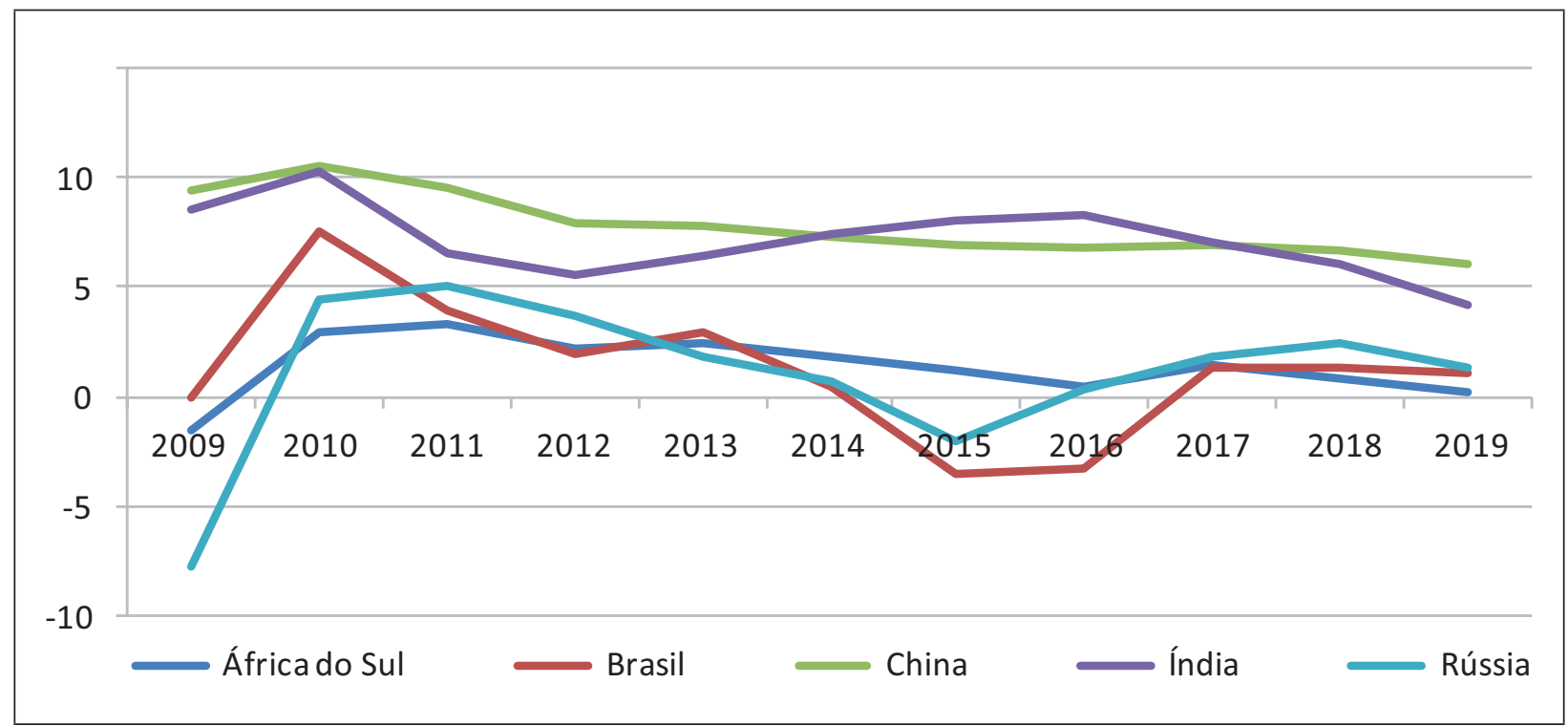

Fonte: Elaboração própria a partir de World Bank (2020).

O comércio intrabloco e a possibilidade de explorar um potencial de aumento sempre esteve entre as expectativas dos governos com relação ao BRICS. Mas como demonstram os gráficos a seguir, Brasil, Rússia e África do Sul têm uma importância secundária na totalidade do comércio internacional da Índia. É possível constatar também que não houve o desejado aumento do comércio entre os países induzido pelo mecanismo BRICS. A exceção ocorre com a China, visto que o comércio sino-indiano teve um aumento gradual no período 2009-2019.

O gráfico a seguir mostra que, entre os países que compõem o BRICS, a China apresenta a maior participação no fluxo de comércio com a Índia. O total do comércio entre os dois países ficou em US\$ 87 bilhões em 2018-2019. 


\section{Figura 2 - Total de comércio (importação + exportação) dos países do BRICS com a Índia em US\$ bilhões}

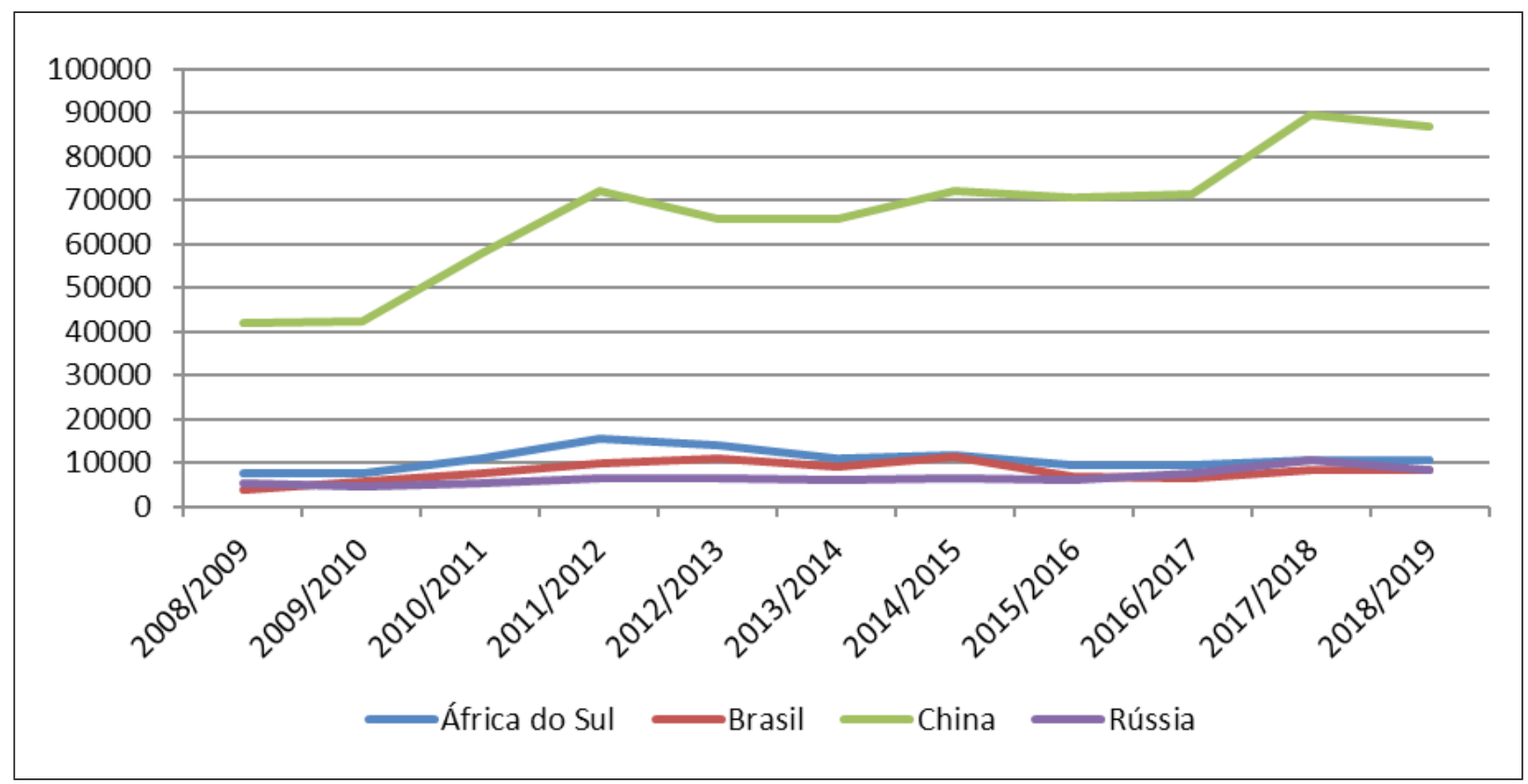

Fonte: Elaboração própria a partir de India, Ministry of Commerce and Industry, Departament of Commerce, Export Import Data Bank (2020).

Como demonstra o Gráfico 3, durante a série 2009-2019, a China se mantém como o maior mercado exportador para a Índia entre os países BRICS. Em 20182019, as exportações indianas para a China fecharam em US $\$ 25.64$ bilhões, representando aproximadamente $5 \%$ do total das exportações da Índia (India, Ministry of Commerce and Industry 2020).

Figura 3 - Exportações da Índia para países do BRICS (em \%) no total das exportações indianas

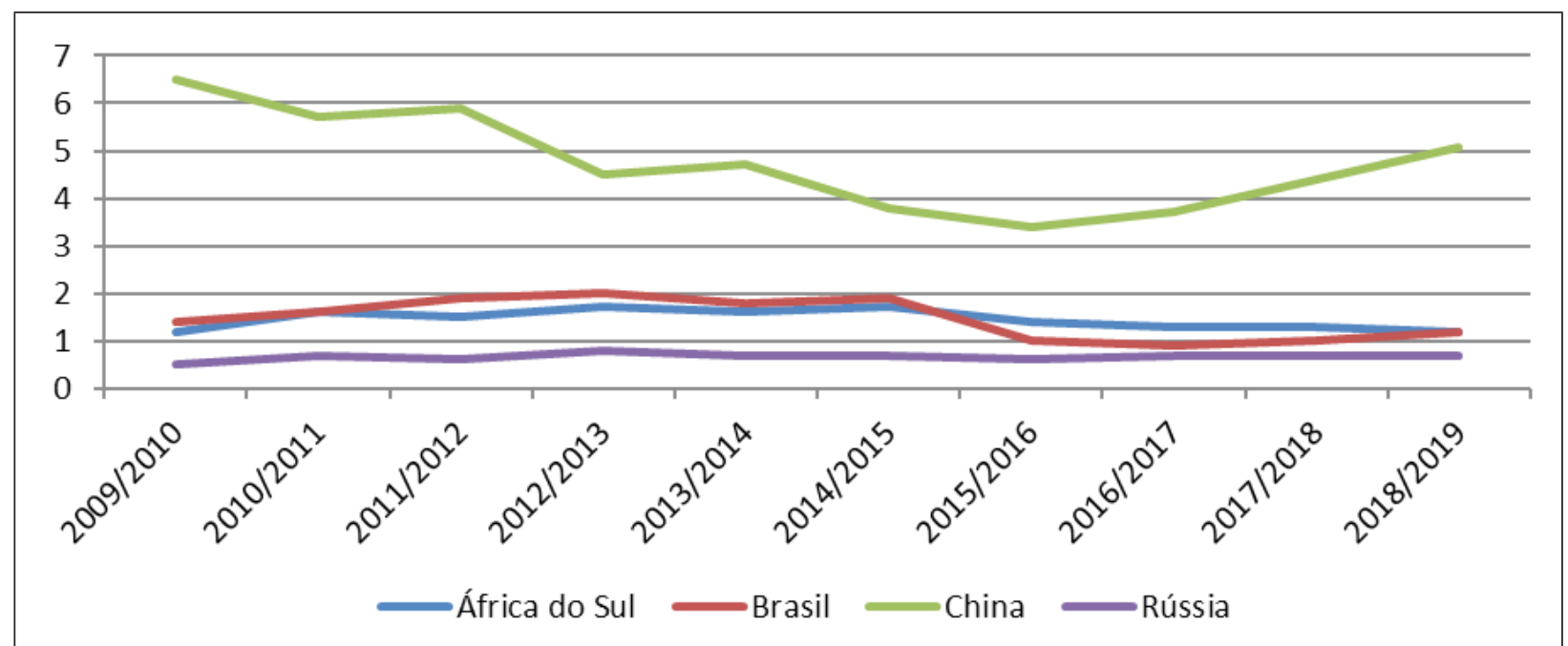

Fonte: Elaboração própria a partir de India, Ministry of Commerce and Industry, Departament of Commerce, Export Import Data Bank (2020). 
No conjunto do comércio intrabloco, o peso da China se sobrepõe aos outros países, o que gera um desequilíbrio. Como se observa nos gráficos 4 e 5 , a China puxa o índice de comércio entre os países do agrupamento.

Figura 4 - Participação no

total de exportações da Índia para os Brics 2009/2010

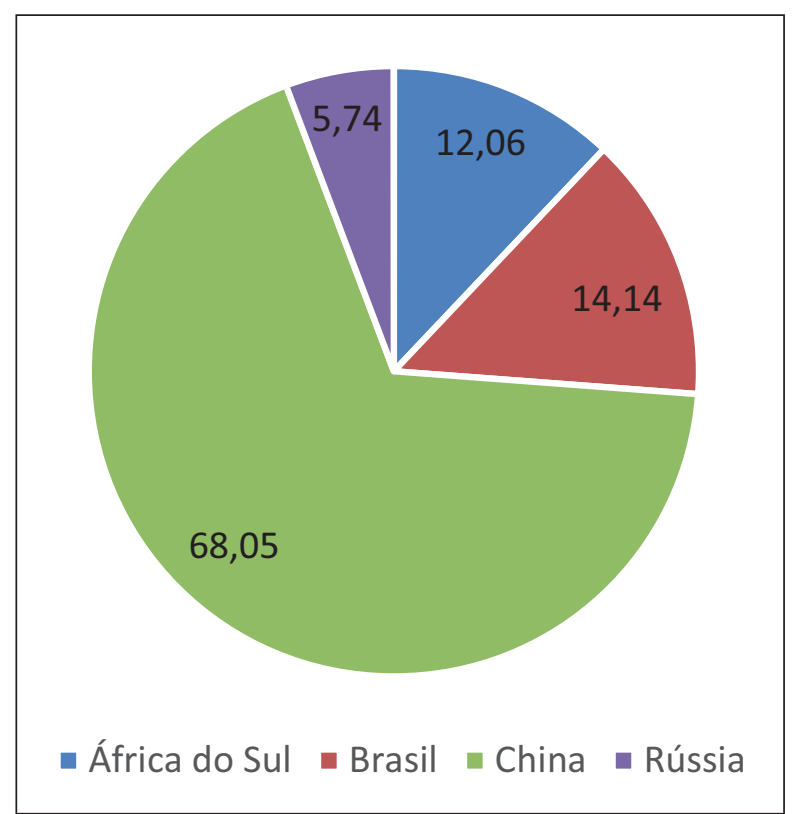

Figura 5 - Participação no total de exportações da Índia para os Brics 2018/2019

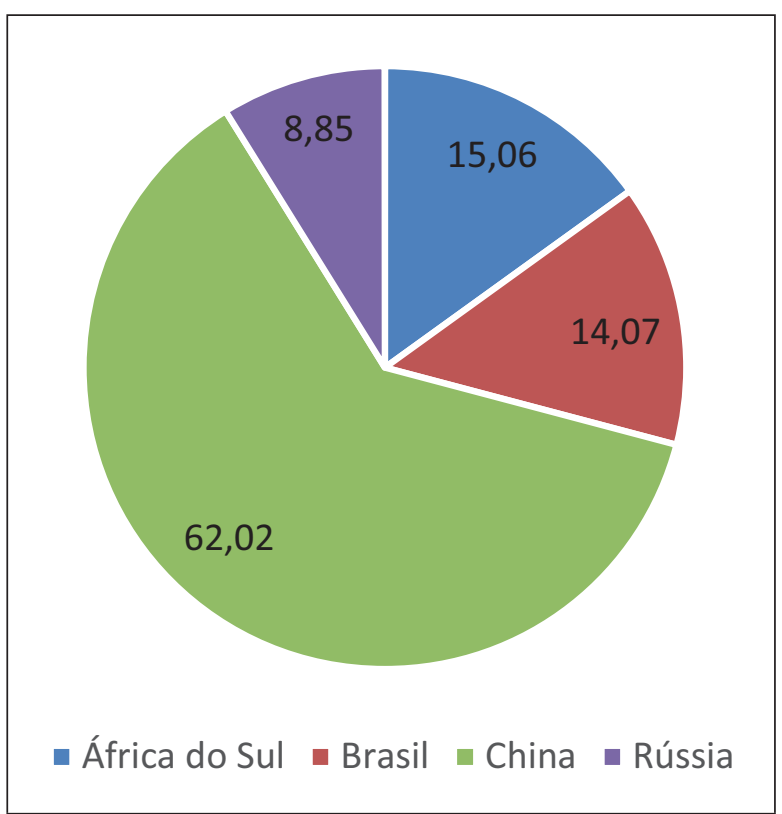

Fonte: Elaboração própria a partir de India, Ministry of Commerce and Industry, Departament of Commerce, Export Import Data Bank (2020).

Se a China fosse retirada do bloco, a dimensão econômica do comércio indiano com o grupo seria bem menor. Com o Brasil e a África do Sul, a perspectiva de crescimento permaneceu limitada, embora sejam parceiros comerciais importantes. A Rússia continua sendo um país grande fornecedor de armamentos. Especificamente com a China, o desequilíbrio favorece o vizinho, uma vez que as importações indianas provenientes da China são bem maiores que as importações chinesas da Índia. No período 2018-2019, as importações oriundas da China fecharam em torno de 70,3 bilhões de dólares, enquanto as exportações, embora em crescimento, ficaram em torno de 11,7 bilhões de dólares (India, Ministry of Commerce and Industry 2020).

Fora da esfera econômica, algumas análises buscam enquadrar a possibilidade de cooperação ao avaliar desde o comportamento dos países dos BRICS nos votos da Assembleia Geral da ONU (Ferdinand 2014; Dijkhuizen e Onderco 2019) até se Rússia e China suportariam os demais membros com mais espaço no Conselho de Segurança da ONU (Jayan 2012). Ferdinand (2014) analisa um longo período, 
desde 1974, de votos na Assembleia Geral e nota alto grau de coerência nos votos dos países do BRICS, levemente aprofundada entre 2008 e 2011. Os votos mais convergentes eram em torno da temática de desenvolvimento, no entanto, os temas de direitos humanos e desarmamento nuclear marcam diferentes posições no grupo, assuntos que China e Índia raramente discordam. A análise sugere também que, a partir da formação do IBAS, os três países estariam mais alinhados nos votos (Ferdinand 2014).

Num estudo mais recente, Dijkhuizen e Onderco (2019) indicam que se há uma convergência nos votos dos países do BRICS na Assembleia Geral da ONU, isso não se revela como um bloco coeso e capaz de ter uma estratégia conjunta. Nessa instância, os países do BRICS nunca patrocinaram uma resolução como um grupo efetivo, pois nunca houve um aumento de cooperação em temas de segurança como desarmamento, Oriente Médio ou colonialismo. A cooperação do BRICS em temas econômicos/financeiros não se transfere para o patrocínio de resoluções na Assembleia Geral da ONU.

Apesar das declarações de cúpula do BRICS ressaltarem a cooperação e o apoio às mudanças na ONU, enquanto Brasil, Índia e África do Sul almejam se tornarem membros permanentes do Conselho da ONU, China e Rússia não declaram abertamente o apoio a esses países. Diferentemente da Assembleia Geral, analisar cooperação do BRICS no Conselho de Segurança não é viável, pois Brasil, Índia e África do Sul não são membros permanentes. Mas, em 2011, quando todos os cinco estiveram no Conselho, sabe-se que na votação da Resolução 1973 (2011), que autorizou o uso da força na Líbia, Rússia, China, Brasil e Índia se abstiveram. Particularmente sobre o conflito da Síria, a partir de 2011, houve uma divisão entre os aliados ocidentais e a China e a Rússia.

Esse movimento na relação entre Rússia e China caminha numa aproximação pela trilha bilateral, mas a sustentação das relações sino-russas se dá na atuação em grupo e em organizações multilaterais como no BRICS, na SCO, na coordenação da Eurasian Economic Union e na iniciativa chinesa Silk Road Economic Belt. O presidente da China, a partir de 2012, Xi Jinping, reconhece a importância do BRICS também como um apoio à Rússia. A cooperação entre Rússia e China leva à interpretação da emergência de uma Grande Eurásia (Joshi e Sharma 2017; Luckin 2019).

A SCO, especificamente, como um organismo regional, equilibra os interesses da China e da Rússia na Ásia Central. Embora compreendida como uma organização regional, a Rússia passou a defender a expansão dos membros da SCO para 
fortalecer estruturas não ocidentais. Nesse processo, Índia e Paquistão tornaramse membros. Enquanto a admissão da Índia foi sustentada pela Rússia, a do Paquistão foi defendida pela China. As características da Índia como secular, democrática e com forte presença na Ásia Central pesaram na sua inclusão. Geopoliticamente, a Índia formalmente admitida na SCO, em 2017, poderia contribuir nos interesses do Ocidente com relação à Rússia e estados asiáticos (Luckin 2019).

A China estrategicamente vem promovendo grande engajamento em instituições multilaterais e regionais. A investida regional mais arrojada é a iniciativa One Belt, One Road, chamada de Belt and Road Iniciative (BRI). Lançado, em 2013, pelo presidente Xi Jinping como um projeto de conectividade e integração econômica, o BRI abrange mais de 60 países por vias marítimas e terrestres, integrando a Ásia e a Europa. Ocorre, no entanto, que essa iniciativa tem profundas implicações estratégicas para a Índia e pressiona as relações bilaterais, uma vez que algumas rotas alcançam áreas sensíveis da segurança indiana. O caso mais emblemático é o corredor que liga a área ocidental da China com o Mar da Arábia, o China-Pakistan Economic Ocean Corridor (CPEC), que passa por um território reivindicado pela Índia e mantido pelo Paquistão. Esse é um dos fatores que leva a Índia a não participar do empreendimento chinês do Belt and Road Iniciative (BRI).

O peso econômico e geopolítico da China dá ao país a condição de ator mais importante do BRICS e, como foi observado por Mukherji (2014), se o BRICS será ou não um grupo coerente, isso dependerá, em grande extensão, das relações sino-indianas. Mas alguns episódios como o de Doklam, em 2017, revelam a potencial rivalidade regional. A oposição chinesa ao desejo da Índia de se tornar um membro permanente do Conselho de Segurança da ONU e da participação indiana do Nuclear Suppliers Group (NSG) também revelam as fissuras nas relações. A aproximação da Índia com os Estados Unidos e o Japão é uma reação clara à ascensão da China e às suas pretensões regionais. Diante de potenciais interesses conflitantes, iniciativas de cooperação como no BRICS podem até se tornar secundárias aos interesses de soberania e geopolíticos desses países (Beeson e Zeng 2018).

Adicionada à peculiaridade das relações entre a China e a Índia, existe regionalmente um baixo bilateralismo no Sul Asiático e, até mesmo, na South Asian Association for Regional Cooperation (SAARC) há uma baixa expressividade de trocas particularmente pela rivalidade histórica entre Índia e Paquistão. Essa 
condição, entre outros fatores apresentados, move a Índia para uma busca e um comprometimento com o multilateralismo, como o BRICS.

\section{Conclusão}

A experiência da Índia no BRICS reside na tradicional ênfase ao multilateralismo da política externa indiana, mas inserida num contexto de uma economia crescente e mais integrada à economia mundial do que em outros contextos, onde o discurso anticolonial era presente. Os elementos pretéritos de identidade e autonomia ainda se mantêm, mas a adesão ao multilateralismo ocidental é parcial e instrumental. Tal situação leva a um multilateralismo seletivo e à construção de arquiteturas multilaterais paralelas àquelas associadas à ordem liberal, sem antagonismos, como o caso do NDB (Ollapally 2018). Somado a essa condição, o BRICS também deve ser entendido do ponto de vista da construção de parcerias estratégicas, uma vez que tanto Singh quanto Modi mantiveram uma rede de parcerias para assegurar a construção da imagem de um grande ator global, como assegurar as possibilidades de coalizões no rol de várias instituições (Basrur 2017).

No decorrer deste artigo, mostrou-se que, na atuação multilateral, o BRICS tornou-se o âmbito de readequação de velhas demandas da Índia por mudanças no FMI, Banco Mundial e ONU, com destaque ao reequilíbrio das cotas do FMI em favor dos países em desenvolvimento. Sobre a temática do desenvolvimento, surgiu da Índia, no governo de Singh e promovida por Modi, a ideia de criação de um Novo Banco de Desenvolvimento, com a finalidade de financiar projetos de infraestrutura e de desenvolvimento sustentável. No período Modi, houve a proposta de projeto para o desenvolvimento da agricultura sustentável e a promoção da segurança alimentar.

Na relação com os demais países do grupo, houve a expectativa inicial de que o comércio intrabloco teria um potencial de aumento, o que, todavia, não concretizou. O crescimento do comércio decorreu em função do papel da China no crescimento do comércio com os demais países do grupo e com a Índia em específico. Paradoxalmente, as relações sino-indianas são profundamente caracterizadas pela simultaneidade de cooperação e conflito. Ao passo que há uma preocupação indiana eminente de que a China use os vizinhos para uma balança de poder no Sul Asiático, o alto patamar de comércio entre China e Índia 
pode conter irrupções mais graves em disputas territoriais. No jogo geopolítico da Eurásia, as relações entre Índia e Rússia também pesam. Mas, se as relações entre Índia e China são caracterizadas por conflito ou cooperação, isso vai depender da perspectiva a ser dada. Apesar de ressalvas, o BRICS encontra-se na esfera da cooperação na relação entre China e Índia e não foi diminuído por episódios como o de Doklam em 2017. Para a Índia, o BRICS está dentro do multilateralismo seletivo e da autonomia estratégica.

\section{Referências}

Alam, Anwar. 2017. India, Non-Alignment and Emerging Global Governance. India Quarterly, 73:3, 273-291, DOI: 10.1177/0974928417716210

Beeson, Mark e Zeng, Jinghan. 2018. The BRICS and global governance: China's contradictory role, Third World Quarterly, 39:10, 1962-1978, DOI: 10.1080/01436597.2018.1438186

Bergenwall, Samuel. 2016. Assessing India's Rise and the Road Ahead, Strategic Analysis, 40:5, 386-404, DOI: 10.1080/09700161.2016.1209905

Basrur, Rajesh. 2017. Modi's foreign policy fundamentals: a trajectory unchanged. International Affairs 93: 1, 7-26, DOI: 10.1093/ia/iiw006

Bric. 2009. Joint Statement of the BRIC Countries' Leaders. Ministry of External Affairs of India. https://www.mea.gov.in/bilateraldocuments.htm?dtl/4824/Joint_Statement_ of_the_BRIC_Countries_Leaders. Acesso em: 20 mar. 2020.

Bric. 2010. II BRIC SUMMIT - Joint Statement. Ministry of External Affairs of India. https://www.mea.gov.in/bilateral-documents.htm?dtl/3983/II_BRIC_SUMMIT_ Joint_Statement. Acesso em: 04 abr. 2020.

Brics. 2011. Sanya Declaration. Ministry of External Affairs of India. https://www.mea. gov.in/bilateral-documents.htm?dtl/4789/Sanya_Declaration. Acesso em: 13 abr. 2020. Brics. 2012. Fourth BRICS Summit - Delhi Declaration. Ministry of External Affairs of India. https://www.mea.gov.in/bilateral documents.htm?dtl/19158/Fourth_BRICS_ Summit_Delhi_Declaration. Acesso em: 15 abr. 2020.

Brics. 2013. 5th BRICS Summit - eThekwini Declaration and Action Plan. Ministry of External Affairs of India. https://mea.gov.in/bilateral-documents.htm?dtl/21482 $/ 5$ th + BRICS + Summit + + eThekwini + Declaration + and + Action + Plan. Acesso em: 05 mar. 2020.

Brics. 2014. Sixth BRICS Summit - Fortaleza Declaration. Ministry of External Affairs of India. Disponível em https://www.mea.gov.in/bilateral-documents.htm?dtl/21482/5th_ BRICS_Summit_eThekwini_Declaration_and_Action_Plan. Acesso em: 12 mar. 2020. 
Brics. 2015. 7th BRICS Summit - Ufa Declaration. Ministry of External Affairs of India. http://www.mea.gov.in/Uploads/PublicationDocs/25448_Declaration_eng.pdf. Acesso em: 17 mar. 2020. 2020.

Brics. 2016. Goa Declaration at 8th BRICS Summit. Ministry of External Affairs of India. https://www.mea.gov.in/bilateraldocuments.htm?dtl/27491/Goa_Declaration_at_8th_ BRICS_Summit. Acesso em: 22 mar. 2020.

Brics. 2017. BRICS Leaders Xiamen Declaration. Ministry of External Affairs of India. http://www.mea.gov.in/Uploads/PublicationDocs/28912_XiamenDeclaratoin.pdf. Acesso em: 23 mar. 2020.

Brics. 2018. 10th BRICS Summit Johannesburg Declaration. Ministry of External Affairs of India. 2018. https://www.mea.gov.in/bilateral-documents.htm?dtl/30190/10th_ BRICS_Summit_Johannesburg_Declaration. Acesso em: 26 mar. 2020.

Brics. 2019. BRASÍLIA DECLARATION 11th BRICS Summit. Ministry of External Affairs of India. http://www.mea.gov.in/Uploads/PublicationDocs/32042_Braslia_ Declaration__1_.pdf. Acesso em: 26 mar. 2020.

Chaturvedi, Sachin, SAHA, Sabyasachi. 2019. Role of BRICS' Economic Cooperation for Global Governance and Institution-Building: An Indian Perspective, Strategic Analysis, 43:6, 558-570, DOI: 10.1080/09700161.2019.1694643

Cozendey, Carlos Márcio. 2015. Visão ou Miragem? Banco de Desenvolvimento e Arranjo de Reservas no Horizonte dos BRICS. In BRICS: estudos e documentos / Renato Baumann... [et al.]. - Brasília: FUNAG.

Dijkhuizen, Frederieke e ONDERCO, Michal. 2019. Sponsorship behaviour of the BRICS in the United Nations General Assembly, Third World Quarterly. 40, 2035-2051, DOI: $10.1080 / 01436597.2019 .1622411$

Ferdinand, Ferdinand. 2014. Rising powers at the UN: an analysis of the voting behaviour of BRICs in the General Assembly, Third World Quarterly, 35:3, 376-391, DOI: $10.1080 / 01436597.2014 .893483$

India. 2020. Ministry of Commerce and Industry. Departament of Commerce, Export Import Data Bank. Disponível em https://commerce-app.gov.in/eidb/. Acesso em: 18 jun. 2020.

Jayan, P.A. 2012. BRICS: Advancing Cooperation and Strengthening Regionalism. India Quarterly 68:4, 363-384. DOI: 10.1177/0974928412467249

Joshi, Nirmala and SHARMA, Raj Kumar. 2017. India-Russia Relations in a Changing Eurasian Perspective. India Quarterly 73(1), 36-52. DOI: 10.1177/0974928416683056

Li, Li (2019). BRICS: A Limited Role in Transforming the World, Strategic Analysis, 43:6, 2019, 499-508, DOI: 10.1080/09700161.2019.1677017

Luckin, Alexander. 2019. Russian-Chinese Cooperation in Central Asia and the Idea of Greater Eurasia. India Quarterly, 75(1), 1-14. 10.1177/0974928418821477 
Miller, Manjari Chatterjee. 2014 Foreign Policy à la Modi: India’s Next Worldview. Foreign Affairs. April 3. https://www.foreignaffairs.com/articles/india/2014-04-03/ foreign-policy-la-modi. Acesso em: 24 jan. 2015.

Miller, Manjari Chatterjee and ESTRADA, Kate Sullivan de. 2017. Pragmatism in Indian foreign policy: how ideas constrain Modi. International Affairs, 93: 1, 27-49. DOI: $10.1093 /$ ia/iiw001

Modi, Narendra. 2014. Prime Minister's statement at the Plenary Session of the 6th BRICS Summit: Inclusive Growth: Sustainable Solutions. Ministry of External Affairs of India. https://www.mea.gov.in/Speeches-Statements.htm?dtl/23636/ Prime_Ministers_statement_at_the_Plenary_Session_of_the_6th_BRICS_Summit_ Inclusive_Growth_Sustainable_Solutions. Acesso em: 25 abr. 2020.

Mukherji, Rahul. 2014. India and Global Economic Governance: From Structural Conflict to Embedded Liberalism. International Studies Review, Vol. 16: 3, 460-466, DOI: $10.1111 /$ misr. 12155

Narlikar, Amrita. India rising: responsible to whom? 2013. International Affairs 89:3, 595-614. DOI: 10.1111/1468-2346.12035

Ollapally, Deepa M. 2018. India and the International Order: Accommodation and Adjustment. Ethics International Affairs, 32:1, 61-74. DOI:10.1017/S0892679418000102

Pant, Harsh V. 2017. The End of Non-Alignment? Orbis. Volume 61:4, 527-540, DOI: $10.1016 /$ j.orbis.2017.08.004

Pant, Harsh V. and SUPER, Julie M. 2015. India's 'non-alignment' conundrum: a twentieth-century policy in a changing world, International Affairs. 91:4, 747-764. DOI: $10.1111 / 1468-2346.12336$

Rajagopalan, Rajeswari P. 2017. Russia-India-China Trilateral Grouping: More Than Hype? A closer look at the development of the mechanism and the drivers behind it. The Diplomat. https://thediplomat.com/2019/07/russia-india-china-trilateralgrouping-more-than-hype/. Acesso em: 04 jun. 2020.

Sakawa, Richard. 2019. BRICS and Sovereign Internationalism, Strategic Analysis, 43:6, 456-468. DOI: 10.1080/09700161.2019.1669899

Shanghai Cooperation Organisation. 2015. UFA Declaration By the Heads of Member States of the Shanghai Cooperation Organization. Disponível em http://eng.sectsco. org/documents/. Acesso em: 15 mai. 2020.

Singh, Manmohan. 2009. Interview of Prime Minister Dr. Manmohan Singh with Financial Times. Ministry of External Affairs, 2009. https://www.mea.gov.in/ interviews.htm?dtl/5003/Interview + of + Prime + Minister + Dr + Manmohan + Si ngh + with + Financial + Times. Acesso em: 02 jun. 2020.

Singh, Manmohan. 2010. Opening Statement by the Prime Minister of India Dr. Manmohan Singh at the Plenary Session of the BRIC Summit 2010. Ministry of External Affairs 
of India. https://www.mea.gov.in/Speeches-Statements.htm?dtl/547/Opening Statement_by_the_Prime_Minister_of_India_Dr_Manmohan_Singh_at_the_Plenary_ Session_of_the_BRIC_Summit. Acesso em: 25 mar. 2020.

Singh, Manmohan. 2011. Statement by Prime Minister at the plenary session of BRICS Leaders 2011. Ministry of External Affairs of India, 2011. https://www.mea.gov.in/ Speeches-Statements.htm?dtl/332/Statement_by_Prime_Minister_at_the_plenary_ session_of_BRICS_Leaders. Acesso em: 25 mar. 2020.

Singh, Manmohan. 2012. Prime Minister's Statement at the Plenary Session of the Fourth BRICS Summit, New Delhi 2012. Ministry of External Affairs. https://www. mea.gov.in/Speeches-Statements.htm?dtl/19107/Prime_Ministers_Statement_at_ the_Plenary_Session_of_the_Fourth_BRICS_Summit_New_Delhi. Acesso em: 26 mar. 2020.

Singh, Manmohan. 2013. Prime Minister's Statement at the Plenary Session of the 5th BRICS Summit, 2013. Ministry of External Affairs. https://www.mea.gov.in/ Speeches-Statements.htm?dtl/21480/Prime_Ministers_Statement_at_the_Plenary_ Session_of_the_5th_BRICS_Summit. Acesso em: 29 mar. 2020.

Tellis, Ashley. 2016. NDA at 2: Modi's Unexpected Successes in Foreign Policy. Hindustan Times. https://www.hindustantimes.com/analysis/nda-at-2-modi-s-unexpectedsuccesses-in-foreign-policy/story-gbDlLeFH7ZuKbxBbWtKwUM.html. Acesso em: 1 jun. 2020.

Thakur, Ramesh. How representative are Brics? 2014. Third World Quarterly, 35:10, 2014, 1791-1808. DOI: 10.1080/01436597.2014.971594

World Bank. 2019. The World Bank. https://data.worldbank.org/. Acesso em: 24 out. 2019.

World Bank. 2020. The World Bank, 2020. https://data.worldbank.org/. Acesso em: 26 abr. 2020.

Wulf, Herbert \& Debiel, Tobias. 2015. India's 'Strategic Autonomy' and the Club Model of Global Governance: Why the Indian BRICS Engagement Warrants a Less Ambiguous Foreign Policy Doctrine, Strategic Analysis, 39:1, 27-43. DOI: $10.1080 / 09700161.2014 .980550$ 